\title{
BIM技术在工程项目管理全过程咨询中的应用研究
}

\author{
孙荣华* \\ 北京金马威工程咨询有限公司 辽宁 沈阳 110001
}

\begin{abstract}
摘要: 随着全过程工程咨询服务的不断完善, BIM技术在全过程咨工程咨询中的优势逐渐凸显, 为了进一步发 挥BIM技术在全过程工程咨询中的应用价值, 本文从 BIM 技术的概念入手, 总结了 BIM技术在全过程工程咨询中的应 用情况，仅供参考。

关键词: BIM技术; 项目管理；全过程；工程咨询

DOI: https://doi.org/10.37155/2661-4669-0308-48
\end{abstract}

\section{Research on the Application of BIM Technology in the Whole Process of Engineering Project Management Consulting}

\author{
Rong-Hua Sun* \\ Beijing Jinmawei Engineering Consulting Co., Ltd., Shenyang 110001 Liaoning China
}

\begin{abstract}
With the continuous improvement of the whole process engineering consulting service, the advantages of BIM technology in the whole process engineering consulting are becoming more and more prominent. In order to give further play to the application value of BIM technology in the whole process engineering consultation, starting with the concept of BIM technology, this paper summarizes the application of BIM technology in the whole process engineering consultation for reference only.
\end{abstract}

Keywords: BIM technology; Project management; Whole process; Engineering consulting

引言

近年来, 伴随着我国建筑行业的快速发展, 在建筑工程领域, 通过全过程工程咨询来为工程造价管理等提供有效 的参考, 使得不同工程主体、部门之间的协调性和融合性得以提高。但因为建筑工程项目中涉及的工程要素非常多, 包含了多个工程流程, 在全过程工程咨询中常常会遇到信息传输不及时等难题。BIM技术通过专有模型的构建, 可以 实现不同工程信息的共享，提升工程咨询的有效性，对工程建设经济效益和社会效益的提升有着重大意义。

\section{BIM 技术在全过程工程咨询中的应用概述}

1.1 BIM技术

建筑信息模型通常是指通过各类工程技术软件描述建筑物的体系和组成元素, 同时对整个建筑的设计、施工与运 维信息进行集成管理和可视化分析, 并完成建筑工程领域的信息集成、交互及协同工作。该模型包含建筑物的信息 模型与建筑工程的管理行为模型两方面内容, 可以在建设全生命周期内将两者进行完美的组合。传统的工程建设过程 中, 信息交换一般通过二维图纸进行, 受沟通方式、理解能力等因素的影响, 在传递过程中, 易导致部分信息损失, 从而造成不利影响。应用BIM技术后, 采用通用的执行标准, 建立信息完备的BIM模型, 描述建筑物的体系和组成元 素, 极大的降低各参建方的沟通壁垒。完善的信息共享服务，也提升了参建单位的工作效率，加快了工程进度 ${ }^{[1]}$ 。

1.2 全过程工程咨询模式

全过程工程咨询指的是业主方为促进项目各参建方的有机融合, 将原来由设计方、监理方、施工方等不同咨询主

*通讯作者: 孙荣华, 男, 汉族, 1976.7.17, 辽宁沈阳, 本科, 注册造价工程师, 一级建造师, 注册监理工程 师, 研究方向: 工程造价、概预算、工程管理。 
体所承担的咨询服务任务统一委托给综合实力较强的咨询单位, 由其完成决策阶段、设计阶段、施工阶段与运营阶段 的全过程工程价值估算任务。通过全过程的工程咨询模式能有效节约资源、缩短工期、提高质量、改进管理。

\section{BIM+ 技术在全过程咨询项目管理中的应用优势}

\section{1 提升工作效率，保证信息完整}

将BIM技术和全过程咨询项目管理有机结合，项目管理多方能够实现共同讨论和实时互动，对项目工程的重难点 和关键节点也能够及时进行把控，打破专业壁垒，强化工作效能。BIM+技术咨询服务的运作打破了过去各自为政的 人员分工方式, 促使各个工作人员能够形成一个有机整体, 彼此保持着更加紧密的联系。项目管理中需要的各种专业 知识也能够相互结合和充分吸收, 实现打造复合型人才的要求。BIM+的全过程咨询项目管理模式, 实现各种数据信 息的集成、更新，项目管理人员能够一同参与其中，促使组织效率有所提高，同时还能够将各种数据信息一键上传到 云端平台，为后续管理工作提供基本的数据保障。

通常而言，全过程咨询项目服务通常需要涉及较长的时间周期，各个板块涉及的工作人员多，受到传统模式的 制约，工作人员难以有效进行沟通，促使咨询人员的工作效率有所降低。在此情况下，开拓BIM管理协同平台能够促 使工程项目内部各个咨询人员进行高效沟通和交流，促使内部管理效率能够得到进步和提升。与此同时，基于BIM模 型, 工作人员也能够更加直观地了解项目工程数据信息, 使建设单位和施工总承包的工作效率也能够实现显著提高, 推动项目工程的顺利完成 ${ }^{[2]}$ 。

2.2 提高资源利用，确保投资合理

BIM+技术在全过程咨询项目管理中具有明显的成本管理优势, 能够有效避免出现资源浪费的情况。BIM通过对 项目工程的虚拟建造, 能够将施工图纸中出现的问题早发现、早解决, 也能有效避免在实际施工作业中造成过多的资 源浪费现象。基于施工图纸可建性，能够在施工作业之前就对项目工程量展开经济性分析，确保每一笔资金投人能够 符合经济效益。现阶段, 我国BIM技术的应用研究正处于不断发展过程中, BIM+的应用能力有限, 如果想充分发挥 $\mathrm{BIM}+$ 技术在全过程咨询项目管理效果, 应当加强技术功能研究, 加大人才培养力度, 使工程管理人员能够实现组织 管理、造价控制水平的提高，促使BIM技术和项目工程管理的融合程度更高，工程建设管理呈现多元化的功效 ${ }^{[3]}$ 。

\section{BIM 技术在全过程工程咨询中的运用}

\section{1 设计咨询阶段}

整个建筑工程项目的实施过程中, 设计阶段是重要的阶段。此阶段的最终目的是要根据工程的总体规划要求来确 定最佳的设计方案。在设计方案确定的过程中, 需综合考虑经济性、技术性等方面的因素。BIM技术虽然在我国有着 多年的发展，但依旧还不够成熟，尤其是在设计咨询阶段，BIM技术还有着广阔的发展空间。设计阶段的工作将直接 影响后续招投标和施工阶段的工作开展，在设计阶段的BIM技术应用，可以有效发挥BIM技术的信息集成优势。为达 到设计咨询的理想效果，各个工程企业在工程实践的过程中，都应该整合传统模式与BIM模式，最大限度地提高BIM 技术的应用水平。我国的很多建筑工程项目实施中, 设计团队在开展相应设计工作时, 依旧采用的是 $\mathrm{CAD}$ 二维设计技 术，而BIM技术则是全过程工程咨询中向设计阶段的延伸技术，从广义上属于三维信息技术的范畴。设计团队或者专 业的设计人员可以通过BIM技术来进行三维模型的构建, 最终所形成的三维设计图纸, 也就可以帮助工程人员更为直 观、清晰地掌握工程的具体情况，使得相应设计问题的发现更为及时和便捷。一旦在工程设计中发现了相应的设计问 题, 就可以直接根据BIM模型中的信息集成情况来进行相应的调整和优化, 使得整个建筑设计方案中的功能、外观或 者空间布局等都较为合适 ${ }^{[4]}$ 。

\subsection{BIM在施工阶段的应用}

在工程建设期间，施工阶段使用BIM技术，其收益最为明显，BIM技术能够有效提高施工单位在对外投标时项目 的中标几率，同时可以通过对数据进行分析，指导企业使用科学使用不平衡报价等其他投标技巧，进而获取更高的经 济效益。由于BIM技术在工程量复核，以及成本优化等领域具有明显的优势。并且基于推广BIM技术的实际需要，湖 南等地区还推出了一系列关于鼓励将BIM技术应用到工程招标过程中的政策，明确其为加分条件或同等条件下优先选 择。在施工准备期间，BIM技术能够做到事前预防以及发现，有效降低施工方案的更改，并且将各种现场技术交底可 
视化, 使其能够能容易被理解及执行。推进施工现场科学管理, 有效提高空间利用效率, 使机械设备使用过程更加优 化，减少资源浪费，提高现场文明施工管理水平，降低安全隐患 ${ }^{[5]}$ 。

3.3 BIM在施工咨询阶段的应用

3.3.1 施工质量管控

使用BIM5D质量安全协同功能, 运用移动端对项目实地信息进行采集, 通过平台的安全信息模型进行处理, 得出 安全系数, 从而预估潜在风险。对于有高风险的部位进行安全技术改进, 确定项目整体质量在线监督, 时时更新, 起 到预防的作用。

\subsection{2 变更管理}

使用BIM5D质量安全协同功能, 运用移动端对项目实地信息进行采集, 通过平台的安全信息模型进行处理, 得出 安全系数, 从而预估潜在风险。对于有高风险的部位进行安全加重保护, 确定项目整体质量在线监督, 时时更新, 起 到预防的作用。

\section{4 运维管理咨询阶段}

运维管理咨询同样属于全过程工程咨询的重点工作。在运维阶段对BIM技术的应用有着非常高的标准和要求, 尤 其是对于商业类地产而言, BIM技术的应用更是可以大大提高运维阶段工程咨询工作的有效性。比如，物联网技术 与BIM技术结合起来以后, 建筑工程的运维管理发生了明显的变化, 推进了智能化大数据运营共享平台的建设, 解决 了传统运维管理模式下所存在的诸多问题。以某特大型建筑为例, 该建筑高 $632 \mathrm{~m}$, 总体建筑面积达到了 $5.741 \times 105$ $\mathrm{m}^{2}$ ，在该建筑投人使用以后，引人了BIM技术来进行全生命周期管理，尤其是在运维管理阶段 ${ }^{[6]}$ 。

\section{4 结束语}

BIM技术是目前国际上较为流行的先进技术和协作管理方法。基于BIM协作平台, 可以实现项目可视化、智能化 和信息化，增强各参建方的交流与互动，进而提升工程质量、进度和安全控制水平，规避传统工作模式的相关风险。

目前, BIM技术在我国建筑行业中的应用尚处于摸索阶段, 多数应用BIM技术的建设项目仅存在于招标文件和合同 中。另外, 各参建方对模型提交的精度要求、BIM软件的载体、应用相关需求和取费模式等, 仍未提供统一且明确的 表述。

一定的认识能力和操作能力, 实现BIM协作平台的操作和管理。鉴于当前我国BIM技术应用现状, 为保证BIM协 作管理工作能够顺利开展，建议建设方考虑以下措施：单独发包BIM模型制作，包括模型融合碰撞检查工作; 在招标 文件中, 对建模人员的资质提出要求, 并细化BIM模型的相关要求, 如对模型精度提出细致要求、同一单项工程各方 建模前应统一使用软件；建立BIM协作管理平台；等等。

\section{参考文献:}

[1]陈元浩.全过程工程咨询项目管理平台在建设工程中的应用研究 [D].长春: 长春工程学院,2020.

[2]李立明,李泓嘉.BIM技术在全过程工程咨询管理中的应用分析[J].中国设备工程,2020(13):230-231.

[3]姚丹.BIM技术在全过程工程咨询项目中的应用探究 [J].工程造价管理,2019(5):11-20.

[4]吕艳.BIM技术在全过程工程咨询的价值与应用方法[J].建筑与预算,2020,(01):9-11.

[5]孙其文.BIM技术在全过程工程咨询的价值与应用方法 [J].中国室内装饰装修天地,2020,(6):84.

[6]马小涛,何榕.刍议BIM技术在全过程工程咨询的价值与应用 [J]. 山东工业技术,2019,(10):128. 